\title{
Entreciencias
}

Entreciencias: diálogos en la Sociedad del Conocimiento

ISSN: 2007-8064

entreciencias@enes.unam.mx

Universidad Nacional Autónoma de México México

\section{Opciones vacunales contra los virus patógenos de porcinos PRRS y PCV2, un binomio frecuente}

Cajero-Juárez, Marcos; Sánchez-Vázquez, Raúl; Valdéz-Alarcón, Juan José; Bravo-Patiño, Alejandro; Nuñez-Anita, Rosa Elvira

Opciones vacunales contra los virus patógenos de porcinos PRRS y PCV2, un binomio frecuente

Entreciencias: diálogos en la Sociedad del Conocimiento, vol. 5, núm. 12, 2017

Universidad Nacional Autónoma de México

Disponible en: http://www.redalyc.org/articulo.oa?id=457650040009

Se autoriza la reproducción total o parcial de los textos aquí publicados siempre y cuando se cite la fuente completa y la dirección electronica de la publicación.

Esta obra está bajo una Licencia Creative Commons Atribución-NoComercial-SinDerivar 4.0 Internacional. 


\title{
Opciones vacunales contra los virus patógenos de porcinos PRRS y PCV2, un binomio frecuente
}

Vaccine options against PRRS and PCV2 pathogenic viruses of swine, a frequent binomial

\author{
Marcos Cajero-Juárez cajeromarco@hotmail.com \\ Universidad Michoacana de San Nicolás de Hidalgo, México \\ Raúl Sánchez-Vázquez savara.25@gmail.com \\ Universidad Michoacana de San Nicolás de Hidalgo, México \\ Juan José Valdéz-Alarcón jjvaldez_a@hotmail.com \\ Universidad Michoacana de San Nicolás de Hidalgo, México \\ Alejandro Bravo-Patiño brapal68@hotmail.com \\ Universidad Michoacana de San Nicolás de Hidalgo, México \\ Rosa Elvira Nuñez-Anita * re.nunez.anita@gmail.com \\ Universidad Michoacana de San Nicolás de Hidalgo, México
}

Marcos Cajero-Juárez, Raúl SánchezVázquez, Juan José Valdéz-Alarcón, et al. Opciones vacunales contra los virus patógenos de porcinos PRRS y PCV2, un binomio frecuente

Entreciencias: diálogos en la Sociedad del Conocimiento, vol. 5, núm. 12, 2017

Universidad Nacional Autónoma de México

Se autoriza la reproducción total o parcial de los textos aquí publicados siempre y cuando se cite la fuente completa y la dirección electrónica de la publicación. Esta obra está bajo una Licencia Creative Commons Atribución-NoComercialSinDerivar 4.0 Internacional.

Recepción: 19 Septiembre 2016 Aprobación: 07 Diciembre 2016

DOI: / 10.21933/J.EDSC.2017.12.204

Redalyc: http://www.redalyc.org/ articulo.oa?id $=457650040009$
Resumen: En la última década, el síndrome reproductivo y respiratorio porcino (PRRS, por sus siglas en inglés) y las enfermedades asociadas al circovirus porcino tipo 2 (PCV2, por sus siglas en inglés), representan una gran preocupación para la industria porcícola, debido a la afectación de los índices productivos. En consecuencia, su presencia va acompañada de cuantiosas pérdidas económicas. Actualmente, en la mayoría de los centros de producción, se utilizan vacunas clásicas, es decir, elaboradas a partir del virus completo viable ó atenuado. En relación al PCV2, se dispone de pocas vacunas de nueva generación, referidas como aquellas obtenidas a través de la tecnología del ADN recombinante, mientras que, únicamente vacunas clásicas están disponibles contra el virus PRRSV. En este manuscrito, revisamos la naturaleza de los virus PRRSV y PCV2, así también, resaltamos la importancia económica, de acuerdo a los datos de prevalencia nacional e internacional. Además, se incluyen datos de nuevas opciones vacunales, en relación con las vacunas comerciales que, en algunos casos, se ha documentado una baja protección contra cepas heterólogas y cepas de reciente aparición. Por un lado, la investigación en vacunas de nueva generación, ha tenido buena aceptación, debido a la posibilidad de seleccionar la información genética del virus para estimular la respuesta inmune protectora del hospedero y, por otro, porque se acelera el desarrollo de vacunas, e incluso, es posible evitar las infecciones de las cuales es responsable el virus vacunal.

Palabras clave: PRRSV, PCV2, Porcino, Virus, Vacunas.

Abstract: In the last decade, the porcine reproductive and respiratory syndrome (PRRS) and diseases associated with type-2 Porcine circovirus (PCV2) have become an increasing concern for the swine industry, because they affect production rates and cause substantial economic losses. Currently, most production facilities use classictype vaccines, elaborated from an attenuated whole virus. As for PCV2, a few newgeneration vaccines are available through recombinant DNA technology, whereas only classic vaccines are available against prrsv virus. This articleaims at reviewing the nature of the PRRS and PCV2 viruses as well as highlighting their economic importance, according to national and international incidence data. Additionally, some data about new vaccine options in relation to commercial vaccines has been included. In some cases, low protection against heterologous strains and of strains of recent appearance has also been documented. Research on new-generation vaccines has been well accepted; on the one hand, by the possibility of selecting virus genetic information, which stimulates the protective immune response of the host and, secondly, because it accelerates the 
development of vaccines, making it possibleto avoid the infections for which the vaccine virus is responsible.

Keywords: PRRSV, PCV2, Porcine, Virus, Vaccinations.

El PRRSV y el PCV2 son dos patógenos presentes en la enfermedad respiratoria porcina. Está bien documentada la interacción entre ellos, de hecho, es frecuente su coexistencia y esto favorece las infecciones bacterianas (Cao et al ., 2016). Resulta interesante saber que el surgimiento de estos virus, es muy cercano uno del otro y, que ambos pueden coexistir en las mismas células diana, es decir, ambos se replican eficientemente en células del sistema inmune, particularmente macrófagos. En la tabla 1, se contrastan algunos datos generales de estos virus.

Tabla 1.

Generalidades de los virus PRRSV y PCV 2.

\begin{tabular}{|c|c|c|c|c|c|}
\hline Virus & Clasificación & Aparición & $\begin{array}{c}\text { Evolución } \\
\text { sustituciones/sitio/año }\end{array}$ & Genoma & Células blanco \\
\hline PRRSV & arteriviridae & $1987-1997$ & $\sim 10^{2}$ & RNA & $\begin{array}{c}\text { Linfoides } \\
\text { (Macrófagos) }\end{array}$ \\
\hline PCV2 & circoviridae & $1991-1998$ & $\sim 1,2 \times 10^{3}$ & sDNA & $\begin{array}{c}\text { Linfoides } \\
\text { (Macrófagos) }\end{array}$ \\
\hline
\end{tabular}

Fuente: Hanada et al ., 2005; Firth et al ., 2009.

En etapas tempranas de la enfermedad es difícil distinguir los signos clínicos asociados a PRRSV y PCV2. El PRRS se caracteriza por un inicio repentino de fiebre en la primera fase de la etapa aguda, que puede inducir el aborto o incluso la muerte de las cerdas entre los 21 y 109 días de gestación. Las complicaciones respiratorias graves se presentan en los cerdos de diferentes edades, particularmente en lechones recién destetados. Mientras que, las enfermedades asociadas al circovirus porcino tipo 2 (PCAVD), son más diversas, incluyen el síndrome de falla multisistémica de desmedro posdestete (PMWS); al complejo respiratorio porcino (PRDC); el síndrome de dermatitis y nefropatía porcina (PDNS); a la pneumonía necrotizante proliferativa y la enteritis granulomatosa (Lee et al ., 2010; Meng, 2013). Los signos clínicos más frecuentes son: la pérdida progresiva de peso, disnea, taquipnea, palidez y en ocasiones diarrea e ictericia. Las lesiones más consistentes en los cerdos afectados se encuentran en los órganos linfoides, el virus causa una disminución en las células linfoides e inflamación granulomatosa, acompañado por la infiltración de cuerpos de inclusión virales intracitoplasmáticos en los macrófagos. Las complicaciones respiratorias en el PCAVD son frecuentes, tal como ocurre en el PRRS.

A continuación se incluye una breve descripción de la organización del genoma de estos virus. 
El PRRSV es un virus envuelto, compuesto por ARN de polaridad positiva, de aproximadamente $15 \mathrm{kDa}$. Se han descrito varios genotipos, estos son, el europeo, el norteamericano y el de alta patogenia (HPPRRS), éste último aislado en China, además, se han descrito nuevas variantes, algunas de ellas presentan cierta regionalización (Zhang et al ., 2016). El genoma del prrsv, contiene dos marcos de lectura grandes (del inglés Open Reading Frame, ORF), el ORF 1a y ORF 1b, y seis ORFS pequeños, numerados del 2 a 7 . El ORF 1a y $1 \mathrm{~b}$ representan alrededor del $75 \%$ del genoma y codifican para proteínas con actividad polimerasa y replicasa. Los ORFS 2 a 7, codifican para seis proteínas estructurales: en el ORF -2 se codifica una proteína N-glicosilada (GP2) de aproximadamente $30 \mathrm{kDa}$; en ORF-3 una glicoproteína de 45-50 $\mathrm{kDa}$ (GP3); en el ORF-4 una glicoproteína de aproximadamente $32 \mathrm{kDa}$ (GP4); en el ORF-5 una proteína glicosilada (GP5) de $25 \mathrm{kDa}$; en el ORF-6 una proteína de membrana no glicosilada de $18 \mathrm{kDa}$ (GP6, o la proteína $\mathrm{M}$ ) y en el ORF-7 una proteína de la nucleocápside (proteína GP7 o N) de $15 \mathrm{kDa}$ (Music y Gagnon, 2010). Se ha reportado que GP5 está implicada en la entrada del virus en las células diana; también se ha planteado que esta proteína está involucrada en la interacción con los receptores desialo adhesina de macrófagos alveolares de cerdo, lo que sugiere un papel fundamental de esta proteína en el proceso de infección (Ansary et al ., 2006). La proteína GP5, es una de las más estudiadas de PRRSV. Además, se ha documentado que al llevar a cabo la inmunización de los animales con viriones purificados de tipo americano de PRRSV, se generan preferentemente, anticuerpos contra la proteína $\mathrm{N}$ (GP7), lo que sugiere una alta inmunogenicidad de dicha proteína. Esto es notable debido a que algunos datos han demostrado que la proteína $\mathrm{N}$ es altamente conservada en los aislamientos de los virus de tipo europeo y norteamericano (Drew et al ., 1995; Zhou et al ., 2006). Algunos autores refieren que el control de este virus puede contribuir, en gran medida, al entendimiento de la interacción virus-sistema inmune de los cerdos (Meng, 2013).

En contraste, el PCV2, es un virus no envuelto, de simetría icosaédrica, con un diámetro de 16-21 nm, contiene un genoma circular cerrado de cadena sencilla de DNA de aproximadamente 1759 a 1768 nucleótidos dependiendo del genotipo, lo que lo hace uno de los virus animales más pequeños. Se han descrito varios genotipos: PCVA, PCVB, PCV2C, PCVD y un nuevo genotipo que aún no se ha caracterizado (Harmon et al ., 2015). El genoma de PCV2 codifica para tres proteínas y una región no codificante involucrada en la regulación de la transcripción y replicación del virus. El ORF1 y ORF2, codifican para las proteínas esenciales para la replicación y para la conformación estructural del virus. El ORF1 codifica para dos proteínas de replicación (Rep y Rep'). En tanto, el ORF2 codifica para la única proteína de la cápside, conocida como proteína E2 (Faurez et al ., 2009). Por lo tanto, E2 es la principal proteína estructural del circovirus y se ha utilizado para distinguir entre los dos serotipos de PCV , es importante mencionar que el PC1 se considera no patógeno. Una caracterización molecular de la proteína E2 reveló un péptido (30-50 
aa de longitud) que fue suficiente para inducir una respuesta inmune (Timmusk, Fossum y Berg, 2006). Esta información es relevante para el diseño de vacunas debido a la probada capacidad inmunogénica.

El estudio de los genomas de PRRSV y PCV2, está siendo enfocado a dilucidar la relación estructura-función de cada uno de sus ORFS, dicha información es útil para el diseño de nueva vacunas, particularmente, en las que se emplea información parcial del virus. La motivación de buscar alternativas vacunales contra los virus PRRSV y PCV 2 está directamente relacionada con su alta prevalencia, la rapidez con la que se diseminan y la inmunosupresión provocada, que en consecuencia, favorece la instalación de confecciones bacterianas. A nivel mundial, se tienen datos epidemiológicos que reflejan la magnitud del problema, por el contrario, en México, son escasos los datos de prevalencia.

Varios estudios epidemiológicos de todo el mundo han demostrado una alta prevalencia de PRRSV y PCV2 en piaras con diferentes grados de tecnificación. Dichos datos muestran que ambos virus podrían considerarse como reemergentes. Al respecto, se reportó el aislamiento de PCV 2 a partir de suero almacenado antes de los primeros aislamientos obtenidos en el Norte de Alemania y México (Jacobsen et al ., 2009; Ramírez-Mendoza et al ., 2009).

Según datos epidemiológicos de PRRSV y PCV 2 , la prevalencia en el mundo varía de acuerdo al periodo estacional en el que se obtienen las muestras, siendo el periodo invernal el que presenta el mayor número de casos. También se debe considerar la tasa de mutación del virus, se ha documentado una alta variabilidad en el genoma, considerando los nuevos genotipos y subgenotipos. Por ejemplo, se alcanzan diferencias en hasta un 60\% entre el genoma de los aislados de PRRSV, según un estudio retrospectivo donde se identificó PRRSV en el Noreste de China (Shang et al., 2012). También, se ha observado un índice alto de mutaciones en las cepas de PCV2, las cuales se aproximan al rango de mutaciones observada en los virus de ARN (Guo et al ., 2010).

En el mundo, PRRSV y PCV 2 tienen una tasa de prevalencia que va del 30 al 60\%, según datos en Norteamerica, China y Europa (Larochelle, D'allaire y Magar, 2003; Li et al ., 2011; Rose et al., 2012). En México, los datos de prevalencia de PRRSV son similares a los observados en el resto del mundo, éstos varían del 20 al $70 \%$ en estudios retrospectivos, en los cuales se analizaron colecciones de suero de zonas conurbadas de la Ciudad de México (Ramírez-Mendoza et al ., 2009; Ramírez et al ., 2008). Referente a PCV 2 , no se tienen datos de prevalencia en México, sin embargo, los registros nacionales indican el aislamiento de este virus en diferentes zonas del país como en el estado de Sonora y Estado de México (Guillermo-Cordero y Torres, 2009). No contar con suficientes datos de prevalencia de PRRSV y PCV 2 en México, es un tema que se podría retomar en los estudios epidemiológicos, con el propósito de fortalecer el seguimiento de programas de vacunación actuales y futuros.

El control de las enfermedades causadas por PCV2 y PRRSV es un desafío para la industria porcícola en todo el mundo. En el año 2006, en Asia se identificó la presencia de un genotipo del virus PRRSV de alta 
patogenicidad (Tornimbene, 2015); a la fecha, esta cepa se ha diseminado en varias regiones de China. Se ha sugerido que la aparición de cepas con mayor capacidad infectiva, precisan de desarrollar nuevas vacunas para su prevención y control, considerando la alta variabilidad que puede presentarse en los nuevos genotipos (Dietze et al. , 2011).

En la vigilancia epidemiológica de PRRSV, actualmente, se usan vacunas clásicas. En cambio, para PCV2, se dispone tanto de vacunas clásicas como de nueva generación (recombinantes). A continuación, se enlistan los nombres de vacunas comerciales empleadas a nivel mundial, es importante hacer notar que, la mayoría de ellas, están elaboradas a partir de aislados de virus de cepas modelo:

- Para PCV2: Circovac de Merial; Fostera PCV Pfizer; Ingelvac Circoflex Boehringer Ingelheim; Porcilis PCV Schering-Plough/ Merck y Vacuna Suvaxyn PCV2 Pfizer.

- Para PRRSV: Ingelvac PRRSV MLV Boehringer Ingelheim; Vacuna inactiva PRRS PROGRESSIS Merial; Porcilis PRRS Intervet; Amervac PRRS Hipra; Ingelvac PRRS ATP Boehringer Ingelheim; Pyrsvac-183 SSYVA ; Fostera PRRS Pfizer; BSL-PS-100 Bestar Ltd; Ingelvac PRRS KV Boehringer Ingelheim Vetmedica y Repro Cyc PRRS-PLE Boehringer Ingelheim.

A pesar de la diversidad de vacunas comerciales, se siguen investigando nuevas opciones que confieran mayor protección. Se ha sugerido que la tasa de mutación es un factor limitante para el desarrollo de vacunas efectivas. Otra limitante es el uso de cepas modelo, tanto para la manufactura de la vacuna, como para los retos in vivo. Justamente, se han identificado diferentes obstáculos para el desarrollo de una vacuna ideal, así como para determinar su efectividad, en comparación con otras invenciones, debido a los mecanismos naturales del virus para evadir la respuesta inmune innata y adaptativa del hospedero, sumado también a la presencia de epítopes virales responsables de la inmunosupresión, en tanto que se dificulta conferir protección contra las diferentes serovariedades del virus (Charerntantanakul, 2012).

La búsqueda de alternativas vacúnales efectivas y seguras constituyen metas que se han visto favorecidas en la última década, apoyadas con el uso de diversas tecnologías y biotecnologías. Las áreas que confluyen en el desarrollo de vacunas son:

- La bioinformática: permite analizar y diseñar genomas o partes del genoma a partir de la información de una base de datos.

- Las tecnologías de secuenciación y síntesis de ácidos nucleicos.

- La ingeniería genética y la genómica comparativa.

Ante este panorama, es posible conocer y manipular el genoma completo de los virus, sintetizar genomas completos, o parte de ellos, y en estudios epidemiológicos, estudiar la composición nucleotídica de éstos patógenos para establecer similitudes entre las cepas modelo y las de reciente aparición. 
Los avances en la bioinformática, a través de software especializado (análisis in silico ), la biología sintética, la ingeniería de proteínas y la producción de anticuerpos recombinantes específicos coadyuvan para la identificación de regiones mínimas de reconocimiento del virus (epítopos mínimos). Por tanto, se puede seleccionar la molécula con la función biológica capaz de inducir una respuesta inmune específica, fuerte y sostenida. Esta ruta se puede utilizar para combinar diferentes genotipos virales, dando origen a vacunas quiméricas, o bien, genomas virales completos autolimitados, y con ello, la posibilidad de generar un nuevo grupo de vacunas para la prevención y el control de las enfermedades producidas por los virus del PRRS y PCV2. Algunos estudios, han descrito la elaboración de nuevas vacunas con buenos resultados, pero las formulaciones aún no están disponibles en el mercado (Silva et al ., 2012).

A continuación se plantean algunas opciones biotecnológicas novedosas para el desarrollo de vacunas, se describen algunas de ellas, en contraste con las vacunas clásicas:

Vacunas clásicas: Estas vacunas están compuestas de microorganismos debilitados, atenuados en su virulencia o virus viables modificados; según el caso, se busca limitar el resurgimiento de la enfermedad. Se caracterizan por provocar fuertes respuestas celulares y humorales y, a menudo, confieren inmunidad de por vida después de una o dos dosis. Sin embargo, la calidad e intensidad de la respuesta inmune depende de las características de la formulación de la vacuna y la naturaleza del agente infeccioso (Lyoo, 2015). Por otro lado, existen algunas desventajas descritas para las vacunas elaboradas con microorganismos viables, como la posibilidad de que el microorganismo atenuado revierta su forma infecciosa. Otra limitación, consiste en que, en algunos casos, las vacunas activas atenuadas confieren protección tardía, y en general tienen que ser refrigeradas para mantener su funcionalidad (Charerntantanakul, 2012). Para la formulación de vacunas inactivadas, se emplean los microorganismos completos inviables, sometiendo al virus patógeno a tratamientos con productos químicos particulares, calor o irradiación. En dichas circunstancias, el virus no puede recuperar su forma infecciosa. Comúnmente, para este tipo de vacunas, no se requiere refrigeración, lo que las hace más accesibles para los consumidores. Una desventaja de las vacunas inactivadas o inactivas, es el bajo nivel de estimulación de la respuesta inmune, en contraste con el producido por las vacunas de virus activos (Lyoo, 2015).

También se han documentado ventajas, por ejemplo, con el uso de una vacuna inactivada de PRRSV se obtuvo como resultado una reducción en el número de fetos positivos al virus y la mejora de la supervivencia del feto, sin embargo, la vacunación no fue suficiente para prevenir completamente la infección por PRRSV adquirida de forma congénita. Estos datos sugieren una alternativa para disminuir la diseminación viral congénita (Karniychuk et al ., 2012).

Las vacunas de subunidades: Estas vacunas consisten en el uso los antígenos virales, obtenidos por manipulación del genoma del virus después del análisis bioinformático. Los antígenos seleccionados, 
teóricamente, poseen características para estimular el sistema inmune. En algunos casos, estas vacunas utilizan epítopos, es decir, zonas de reconocimiento esenciales para iniciar la generación de anticuerpos específicos, además, las vacunas de subunidades pueden contener uno o más antígenos para garantizar su función (vacunas de subunidades recombinantes). Es posible fabricar las moléculas antigénicas virales mediante el uso de tecnología de ADN recombinante (Ooms, et al .2013).

Recientemente se estan llevando a cabo diversos estudios puntuales para describir la función de cada una de las diferentes proteínas estructurales y no estructurales de los virus, que son responsables de la replicación, la virulencia e inmunidad (Xiong et al ., 2015; Cao et al ., 2016; Rascón-Castelo et al ., 2016).

En la tabla 2, se incluye información de vacunas de nueva generación patentadas para PRRSV y PCV2 donde se emplean subunidades de los virus. Algunos datos interesantes de la generación de vacunas contra serotipos específicos son: la selectividad contra ese serotipo o variante; la generación de vacunas basadas en antígenos esenciales universales, las cuales han resultado en candidatos a vacuna con buenas expectativas. En este último caso, se considera la utilización de los fragmentos genómicos responsables de la patogenicidad y la inmunidad, sugiriendo una mayor capacidad protectora. Otro aspecto importante es la evaluación de la respuesta inmune fuerte y sostenida, considerando los cambios del virus a través de sus ciclos de replicación.

Tabla 2

Patentes vigentes en el año 2017

\begin{tabular}{|c|c|}
\hline $\begin{array}{l}\text { Patente vigente } \\
\text { en al año } 2016\end{array}$ & PRSSV \\
\hline WO200602193 & Basada en subunidades del orf1 de prrsv \\
\hline WO201025109 & Elaborada a partir de la cepa de alta patogenicidad de prasv. \\
\hline CA2102036 & Vacuna de subunidades a partir de la Cepa pras lowa \\
\hline CA2410694 & Vacuna de ADN contra PRRSv, empleando uno o varios de los orfs $2,3,4,5,6$ ó 7 . \\
\hline US20080311143 & Vacuna quimérica basada en la cepa Norteamericana, cepa virulenta y avirulenta. \\
\hline WO9640932 & Vacuna de péptidos (subunidades) a partir de la Cepa prrs lowa, orfs 2 y 3. \\
\hline WO2008153572 & Vacuna quimérica contra PRRSV basado en los orfs 1,2 y 3 de la cepa Norteamericana. \\
\hline Patente & PCV2 \\
\hline US20140322267 & Vacuna basada en el orf2 de pcV2 subtipo a (PCva). \\
\hline WO200776520 & Vacuna multivalente contra PCV2, empleando la proteína E2 recombinante completa. \\
\hline US20150056248 & Vacuna de subunidad contra pcr2 subtipo b. \\
\hline US20150093404 & Vacuna de PCV2 basada en el orf 2 subtipo 2 con una mutación en el sitio BC. \\
\hline
\end{tabular}

Fuente: Plataforma en línea Orbit Questel IP Bussiness Intelligence

$\mathrm{L}$ as vacunas de ADN: Se ha propuesto que tienen un alto potencial en la medicina veterinaria, considerando la dificultad de mantener la cadena de frío necesaria para mantener la viabilidad de otro tipo de vacunas. En particular, las vacunas de ADN utilizan fragmentos de ácidos nucleicos, que pueden ser previamente diseñados y sintetizados de novo . Además, las 
vacunas de $\mathrm{ADN}$ son relativamente fáciles y rápidas de diseñar y producir. Recientemente, se ha descrito una vacuna de ADN para PRRSV, que tiene como objetivo prevenir la diseminación del genotipo HP-PRRSV. Los datos mostraron que se mejora la respuesta inmune y proporciona protección inmediata, y a largo plazo. Los autores proponen que esta vacuna de ADN podría ser un candidato atractivo para la prevención y control de PRRS (Du et al ., 2012). En otro estudio, se probaron varias vacunas de $\mathrm{ADN}$ en cerdos, elaboradas cada una de ellas, con información de distintos ORFS del virus PRRSV. Los resultados mostraron que, a pesar de inducir la respuesta inmunológica esperada, ésta no fue suficiente para prevenir la enfermedad (Petrini et al ., 2013).

Las vacunas de particulas virales sin genoma (particulas similares a virus o VLP ): Con la información del virus, se pueden obtener por síntesis química genomas parciales o completos del virus, además, se puede seleccionar la información, de tal manera que se expresen únicamente las proteínas de cápside. Es decir, selectivamente se pueden expresar in vitro los genes de la cápside viral, empleando un sistema de expresión recombinante heterólogo. Se conocen varios sistemas de expresión, entre éstos, células animales, células de insecto, ciertas bacterias y levaduras. Una vez purificadas, las VLP se introducen en el organismo para estimular la respuesta inmune humoral y celular. Las VLP son interesantes como candidatos a vacunas debido a sus propiedades inherentes, es decir, antígenos multiméricos no infecciosos (Crisci, Bárcena y Montoya, 2012). Se han documentado algunas vacunas de tipo VLP contra PRRSV, Binjawadagi., et al . (2016), reportaron una vacuna que contiene cinco proteínas de la superficie viral, sin embargo, sugieren que es necesario mejorar su inmunogenicidad y eficacia. García et al ., (2016) obtuvieron una vacuna que posee cinco proteínas del virus, los autores sugieren que podría ser una alternativa potencial, sin embargo, resta realizar análisis en estudios in vivo. Por su parte, Hu et al ., (2016), desarrollaron una vacuna bivalente tipo VLP con información de proteínas de PCV2, y de PRRSV, la cual mostró buenos resultados de inmunogenicidad en modelos murinos.

\section{Conclusión}

El control de las enfermedades producidas por PCV2 y PRRSV es un tema importante en la porcicultura nacional, considerando las continuas pérdidas económicas y las implicaciones en la salud animal. Resulta interesante la investigación en la generación de vacunas que no requieran el uso de microorganismos completos. Actualmente, es posible diseñar vacunas con mayor capacidad protectora a partir del conocimiento de la relación estructura-función de las proteínas que constituyen a los virus. Las herramientas biotecnológicas facilitan y aceleran el desarrollo de nuevos antígenos específicos, que podrían conducir a la producción de vacunas más eficientes y seguras. 


\section{Agradecimiento}

Agradecemos el financiamiento de PRODEP SEP-Conacyt (157876) e Infraestructura de Conacyt (infr-2015-01 255010).

\section{Referencias}

Ansari, I.H., Kwon, B., Osorio, F.A. y Pattnaik, A.K. (2006). Influence of Nlinked glycosylation of porcine reproductive and respiratory syndrome virus GP5 on virus infectivity, antigenicity, and ability to induce neutralizing antibodies. Journal of Virology, 80 (8), 3994-4004.

Binjawadagi, B., Lakshmanappa, Y.S., Longchao, Z., Dhakal, S., Hiremath, J., Ouyang, K., Renukaradhya, G.J. (2016). Development of a porcine reproductive and respiratory syndrome virus-like-particle-based vaccine and evaluation of its immunogenicity in pigs. Arch Virol, 161 (6),1579-1589. http://dx-doi.org/10.1007/s00705-016-2812-0

Cao, Q.M., Subramaniam, S., Ni, Y.Y., Cao, D., Meng, X.J. (2016). The non-structural protein Nsp2TF of porcine reproductive and respiratory syndrome virus down-regulates the expression of Swine Leukocyte Antigen class I. Virology, 491, 115-124.

Charerntantanakul, W. (2012). Porcine reproductive and respiratory syndrome virus vaccines: Immunogenicity, efficacy and safety aspects. World J Virol , 1, 23-30.

Crisci, E., Bárcena, J. y Montoya, M. (2012). Virus-like particles: The new frontier of vaccines for animal viral infections. Vet Immunol Immunopathol, 148, 211-225.

Dietze, K., Pinto, J., Wainwright, S., Hamilton, C. y Khomenko, S. (2011). Porcine reproductive and respiratory syndrome (PRRS) virulence jumps and persistent circulation in Southeast Asia. Focus on. Food and Agriculture Organization of the United Nations, 5, 1-8.

Drew, T.W., Meulenberg, J. M., Sands, J. J. y Paton, D. J. (1995). Production, characterization and reactivity of monoclonal antibodies to porcine reproductive and respiratory syndrome virus.J Gen Virol , 76, 1361-1369.

Du, Y., Qi, J., Lu, Y., Wu, J.,Yoo, D., Liu, X., Wang, J. (2012). Evaluation of a DNA vaccine candidate co-expressing GP3 and GP5 of porcine reproductive and respiratory syndrome virus (PRRSV) with interferon $\alpha /$ $\gamma$ in immediate and long-lasting protection against HP-PRRSV challenge. Virus Genes , 45, 474-487.

Faurez, F., Dory, D., Grasland, B., Jestin, A. (2009). Replication of porcine circoviruses. Virol J, 6 (60), 1-8.

Firth, C., Charleston, M.A., Duffy, S., Shapiro, B., Holmes, E.C. (2009). Insights into the evolutionary history of an emerging livestock pathogen: porcine circovirus 2.J Virol, 83, 12813-12821.

García, M., Costa, S., Sarraseca, J., de la Roja, N., García, J., García, I. y Rodríguez, M.J. (2016). Generation of porcine reproductive and respiratory syndrome (PPRS) virus-like-particles (VLPS) with different protein composition. JVirol Methods, 236, 77-86.

Guillermo-Cordero, J. L. y Torres, M. A. (2009). Epidemiología del circovirus porcino tipo 2. Bioagrociencias , 2 (2), 4-17. 
Guo, L. J., Lu, Y. H., Wei, Y. W., Huang, L. P. y Liu, C.M. (2010). Porcine circovirus type 2 (PCV2): genetic variation and newly emerging genotypes in China. Virol J , 7, 273.

Hanada, K., Suzuki, Y., Nakane, T., Hirose, O. y Gojobori, T. (2005). The origin and evolution of porcine reproductive and respiratory syndrome viruses. Mol. Biol. Evol, 22, 1024-1031.

Harmon, K.M., Gauger, P.C., Zhang, J., Piñeyro, P.E., Dunn, D. y Chriswell, A.J. (2015). Whole-Genome Sequences of Novel Porcine Circovirus Type 2 Viruses Detected in Swine from Mexico and the United States. Genome Announc, 3 (6). http://dx.doi.org/10.1016/j.jviromet.2016.03.021

Hu, G., Wang, N., Yu, W. y Wang, Z. (2016). Generation and immunogenicity of porcine circovirus type 2 chimeric virus-like particles displaying porcine reproductive and respiratory syndrome virus GP5 epitope B. Vaccine, 34 (16), 1896-1903.

Jacobsen, B., Krueger, L., Seeliger, F., Bruegmann, M., Segal'es, J. y Baumgaertner, W. (2009). Retrospective study on the occurrence of porcine circovirus 2 infection and associated entities in Northern Germany. Vet Microbiol , 138 (1-2), 27-33.

Karniychuk, U.U., Saha, D., Vanhee, M., Geldhof, M., Cornillie, P., Caij, A.B., y Nauwynck, H.J. (2012). Impact of a novel inactivated prrs virus vaccine on virus replication and virus-induced pathology in fetal implantation sites and fetuses upon challenge. Theriogenology, 78 (7), 1527-1537.

Larochelle, R., D'allaire, S., Magar, R. (2003). Molecular epidemiology of porcine reproductive and respiratory syndrome virus (PRRSV) in Québec. Virus Res, 96 (1-2), 3-14.

Lee, D., Han, D., Song, J.Y., Lee, Y.S., Kang, K.S. y Yoon, S. (2010). Genomic expression profiling in lymph nodes with lymphoid depletion from Porcine Circovirus 2-infected pigs. J Gen Virol, 91, 2585-2591.

Li, B., Fang, L., Guo, X., Gao, J., Song, T., Bi, J., y Xiao, S. (2011). Epidemiology and evolutionary characteristics of the porcine reproductive and respiratory syndrome virus in China between 2006 and 2010. Journal of Clinical Microbiology, 49, 3175-83.

Lyoo Y.S. (2015). Porcine reproductive and respiratory syndrome virus vaccine does not fit in classical vaccinology. Clinical and Experimental Vaccine Research , 4, 159-165.

Meng, X-J. (2013). Porcine Circovirus Type 2 ( PCV2 ): pathogenesis and interaction with the immune system. ANNU REV ANIM BIOSCI , 1, 43-64.

Music, N., Gagnon, C.A. (2010). The role of porcine reproductive and respiratory syndrome ( PRRS ) virus structural and non-structural proteins in virus pathogenesis. Anim Health Res Rev , 11 (2),135-163.

Ooms, K., Van Gorp, H., Botti, S., Van Gaever, T.. Delputte, P. L. y Nauwynck, H. J. (2013). Evaluation of viral peptide targeting to porcine sialoadhesin using a porcine reproductive and respiratory syndrome virus vaccinationchallenge model. Virus Res , 177 (2),147-55.

Petrini, S., Ramadori, G., Borghetti, P., Villa R., Borghetti, P., De Angelis, E., y Maura Ferrari, M. (2013). Evaluation of Different DNA Vaccines against Porcine Reproductive and Respiratory Syndrome ( PRRS ) in Pigs. Vaccines , I, 463-480.

Ramírez, E., Moreno, V., Díaz, N., Osorio, F., Ruiz, A., Neira, V. y Quezada, M. (2008). Evaluation of the pathogenicity and transmissibility of a 
chilean isolate of porcine reproductive and respiratory syndrome virus. Transbound Emerg Dis , 55, 115-24.

Ramírez-Mendoza, H., Castillo-Juárez, H., Hernández, J., Correa, P., Segalés, J. (2009). Retrospective serological survey of Porcine circovirus-2 infection in Mexico. Can J Vet Res , 73, 21-24.

Rascón-Castelo, E., Burgara-Estrella, A., Mateu, E., Hernández, J. (2015). Immunological features of the non-structural proteins of porcine reproductive and respiratory syndrome virus. Viruses , 7(3), 873-886. htt p://dx.doi.org/10.3390/v7030873 .

Rose, N., Opriessnig, T., Grasland, B. y Jestin, A. (2012). Epidemiology and Transmission of Porcine Circovirus Type 2 (PCV2). Virus Res, 164, 78-89.

Shang, Y., Wang, G., Tian, H., Yin, S., Du, P., Wu, J., y Liu, X. (2012). Molecular epidemiological investigation of porcine reproductive and respiratory syndrome virus in Northwest China from 2007 to 2010. Virus Genes, 45, 90-7.

Silva, J.A., De Carvalho, O.V., Silva, L.H., Lopes Rangel, J. F., Pires, M., De Almeida M.R. (2012). Porcine Circovirus 2: immunopathogenesis and recent developments in vaccines. World J Vaccines , 2 (2), 96-104.

Timmusk, S., Fossum, C., Berg, M. (2006) Porcine circovirus type 2 replicase binds the capsid protein and an intermediate filament-like protein. $J$ Gen Virol, 87, 3215-23.

Tornimbene, B., Frossard, J.P.,Chhim V., Sorn S., Guitian, J. y Drew, T.W. (2015). Emergence of highly pathogenic porcine reproductive and respiratory syndrome (HP-PRRS) in medium-scale swine farms in southeastern Cambodia. Prev Vet Med, 118 (1), 93-103.

Xiong, D., Song, L., Zhai, X., Geng, S., Pan, Z., Jiao, X. (2015). A porcine reproductive and respiratory syndrome virus ( PRRSV) vaccine candidate based on the fusion protein of PRRSV glycoprotein 5 and the Toll-like Receptor-5 agonist Salmonella Typhimurium FljB . BMC Vet Res, 11 (1),121. http://dx.doi.org/10.1186/s12917-015-0439-0 .

Zhang, Q., Xu, X., You, S., Li, Y., Wang, H., Bai, J., Jiang, P. (2016). Emerging of two new subgenotypes of porcine reproductive and respiratory syndrome viruses in Southeast China. Microb Pathog, 97, 27-33. http://dx.doi.org/ 10.1016/j.micpath.2016.05.011

Zhou, Y. J., An, T.Q., Liu, J.X., Qiu, H. J., Wang Y. F. y Tong G.Z. (2006). Identification of a conserved epitope cluster in the $\mathrm{N}$ protein of porcine reproductive and respiratory syndrome virus. Viral immunol, 19, 383-390.

\section{Notas de autor}

Autor de correspondencia, correo electrónico: re.nunez.anita@gmail.com 